\title{
Future for magnetic fusion
}

SIR - On 22 February 1983 the General Accounting Office (GAO) released a preliminary report that I had requested last year on the status of the Department of Energys (DoE)'s implementation of the Magnetic Fusion Engineering Act of 1980.

The request for the study was made in January 1982 in response to the Reagan Administration's proposed budget cuts in the US magnetic fusion programme, and the subsequent resignation of Dr Edwin Kintner, associate director of the Office of Fusion Energy at the Department of Energy, in protest at these cuts. I felt strongly at that time that the Administration's cuts were undercutting and circumventing the intent of the Magnetic Fusion Engineering Act, and subsequently Congress's ability to make choices that would allow the goals of the act to be met. By so severely restricting the funding for research into magnetic fusion energy, DoE was restricting and possibly eliminating its ability to follow through with the provisions of the act that had received such overwhelming support in 1980.

The report by GAO found that DoE was changing its plans to follow through with the provisions of the Magnetic Fusion Engineering Act, and had not informed Congress, the architects of the act, of these decisions. GAO states, "Citing budgetary constraints, DoE no longer plans to follow through the act's intended development strategy", and yet Congress has received no notice of such action, and thus continues to assume that the provisions of the act are being adhered to in DoE planning.

In further examining the intent of the act, GAO states: "In addition to changing development strategy, experts, including the National Academy of Science's National Research Council, are also questioning whether DoE is adequately pursuing alternative concepts so that options are available when the decision is made to construct the next level reactor'. By further abandoning the development provisions of the Magnetic Fusion Engineering Act, and limiting research into alternative concepts of magnetic fusion (that is, research not a part of the lead tokamak project at Princeton University) the United States will have little choice when the time comes to pursue the next phase set out in the act.

The act foresaw the advancement of several magnetic fusion concepts such as mirrors, stellerators and bumpy toruses, in addition to tokamaks, so that an informed decision could be made about which concept to pursue toward commercial viability. Mirrors, the most advanced of the alternative concepts, may not even be ready for comparison when that time comes. GAO states:

The Mirror Fusion Test Facility (MFTF) is presently under construction. It is a larger facility than the Tandem Mirror Experiment, comparable in size to the Tokamak Fusion Test Reactor. Scientists also hope to demonstrate scientific breakeven on the Mirror Fusion Test Facility before DoE makes a decision on the confinement concept to be used in the next level fusion reactor. DoE expects to make this decision in 1987. However, since funding reductions have delayed construction of the MFTF until at least 1985, it appears unlikely that scientific comparability between tokamaks and mirrors will be achieved by 1987.

Thus the possibility of a knowledgeable and informed choice based on adequate scientific information, as specifically required in the Magnetic Fusion Engineering Act, is impossible. But again, Congress has not been advised of this policy change.

The result of current policy is that due to funding reductions insisted upon by the current Administration, we are faced with a programme whose directions and goals are being changed by bureaucrats forced to function within these budgetary constraints. Congress is being kept uninformed regardless of current law that specifically requires such information at frequent intervals. And we have a programme whose purpose is being abandoned in the name of cost savings, with no eye to its future benefits.

It is clear from the GAO report that DoE is disregarding the crucial legislation that Congress intended to be the framework for the national magnetic fusion effort. If this nation is ever to reach the goals of clean, safe, unlimited fusion energy, we must refocus our efforts and follow through with the Magnetic Fusion Engineering Act.

House of Representatives,

FORTNEY H. STARK

Washington, DC, USA

\section{Where intelligence tests fail}

SIR - Recent attempts to adjust the mean IQ scores of Japanese and American samples (Nature 24 Fcbruary, p.655) may have left unstated the lack of theoretical resolution that attends inter-generation or cross-cultural test score comparisons. All psychological inference from performance demands firm construct validity. Nevertheless, the legacy of the testing paradigm is the need for an agreed structure of intellect. Since Spearman's general factory theory, one revision every decade has emerged: and the names of Thurstone, Burt, Thomson, Ciuildford, Cattell, Carroll and Sternberg are linked with various notable attempts. Their efforts testify to IQ score complexity but admit no ccrtainty.

Given disagreement in the parent culture, transposition of a test to a host culture requires proof of psychological cquivalence before means are compared. For more than forty years cross-cultural psychologists have pursued a set of procedures to establish equivalence. A great variety of approaches have been tried. Specialists in this area would recognize the contributions of Biesheuvel, Coffman, Mellenbergh, Poortinga, Schoeneman, van der Flier and Vester. Their work too is still far from complete. Consequently, psychologists who venture across cultures or generations with test scores as dependent variables facc scientific hazards. Double jeopardy awaits those who risk crosscultural and inter-generational comparisons at one and the same time.

The problems of equivalence within generations may be understood thoroughly; but within-culture-acrossgeneration issues have not had close conceptual, let alone empirical analysis. The most tenuous comparison of all, across generations-across cultures, points in the direction of a reductio ad absurdum. The general practice of inference from group averages requires scientific credibility: and this, at the moment, cannot be guaranteed'.

\section{Plymouth Polytechnic, UK}

S.H. IRVINE

1. Irvinc, S.H. Bull. Br. psychol. Soc. 36, 55-56 (1983).

\section{Power corrupted}

SIR - In the recent note referring to Hooke's Micrographia (Nature 3 March, p.9) it was stated that this "was the first book in English to be devoted to microscopy". This is not so. This magnificent work has many claims to fame but being the first in its field in English is not one of them. Published in 1665, it was anticipated by Henry Power's Experimental Philosophy, which appeared the previous year and of which the microscopical part had been prepared some years earlier. This, as part of its extensive title informs us, was written In Three Books: Containing New Experiments, Microscopical, Mercurial, Magnetical. Thus, like Hooke's Micrographia, its contents are not confined to microscopy.

Power's microscopical observations cover a wide range of objects, both animate and inanimate, and include some truly original work on biological materials. Clearly, concisely and entertainingly written, the book suffers from the lack of that feature which makes the Micrographia so attractive - its splendid plates - for it contains no more than a few crude sketches by way of illustrations: nor can its text be said to be the equal of Hooke's. Nevertheless, for its time it was a work of considerable merit, and among its distinctions is that of being the first book in English to be devoted to microscopy.

GEOFFREY FRYER

Freshwater Biological Association,

Ambleside, Cumbria, UK 